\title{
Happy 91st, Cathleen Synge Morawetz
}

\author{
Allyn Jackson
}

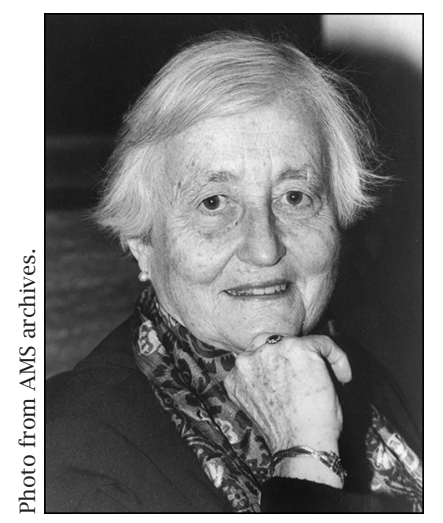

Cathleen Synge Morawetz is a legendary and beloved figure in mathematics. Renowned for her striking work in analysis, she has been an inspiration to many in the field, particularly to women, as well as a leader in the AMS and in the scientific profession more broadly. Her 91st birthday, which occurs in May of this year, is a fitting time to pay tribute to her life.

Her great-uncle was John Millington Synge, the Irish playwright best known for Playboy of the Western World, which caused Morawetz riots when it was first performed in 1907. Her father was John Lighton Synge, an Irish mathematician who had a long career at the University of Toronto; her mother also had some training in mathematics. When Cathleen Morawetz received the AMS Steele Prize for Lifetime Achievement in 2004, she credited her father with instilling the ideal of intellectual achievement and her mother with instilling ambition, which, Morawetz commented, was "at the time very unladylike."

On the various occasions when Morawetz has discussed her long career ${ }^{1}$, she has put the emphasis not so much on herself but on the people around her who helped her succeed. Among these

Allyn Jackson is senior writer and deputy editor of the Notices. Her email address is axj@ams.org.

${ }^{1}$ See in particular the video interviews and excellent article, by Siobhan Roberts, on the "Science Lives" website of the Simons Foundation, http://www. simonsfoundation. org/category/features/science-lives/.

DOI: http://dx.doi.org/10.1090/noti1123 was Cecilia Krieger, who fled Poland during World War I and earned a Ph.D. in mathematics at the University of Toronto, later becoming a professor there. At a crucial moment in Cathleen's final year as a mathematics major at Toronto, Krieger encouraged Cathleen to attend graduate school and promised to find funding.

Krieger came through on the promise, and Cathleen became a graduate student at New York University. There were few women in the doctoral program, but the atmosphere was supportive, partly because of the influence of Richard Courant: He had been a strong mentor for Emmy Noether in Göttingen and continued to encourage women in mathematics after he had emigrated to New York. One of Morawetz's first serious mathematical undertakings was the editing of the now-classic book Supersonic Flow and Shock Waves (1948) by Courant and Kurt Friedrichs. Morawetz said that, despite her junior status, she had standing with the two professors because she could correct their English. Editing this book was one of her formative experiences in mathematics.

Courant was forceful and outgoing, while Friedrichs was shy and a bit withdrawn. Morawetz worked well with both. She flourished in the stimulating atmosphere of what later came to be called the Courant Institute of Mathematical Sciences, which drew no borders between pure and applied mathematics. She was hooked by problems of transonic flow through contact with Friedrichs, who became her thesis advisor, and with Lipman Bers. The support of Courant was crucial as Morawetz followed a very nonstandard career path while she bore and raised four children. She earned her Ph.D. in 1951 and, after a postdoc at the Massachusetts Institute of Technology, she returned to the Courant Institute as a faculty 
member in 1955 and remained there for the rest of her career. She continued to draw inspiration from those around her at the Courant Institute, learning about problems in magnetohydrodynamics from Harold Grad and about wave propagation from Joseph Keller.

Asked whether she is a problem solver or a theory builder, Morawetz replied, "I am an applied mathematician who proves theorems to solve problems." She has taste both for the mathematics and for the choice of problems from other areas. One gets a sense of this taste from two of her expository articles. The first is the writeup of her 1981 AMS Gibbs Lecture, "The mathematical approach to the sonic barrier" (Bulletin of the AMS, March 1982). The article provides clear, down-toearth explanations of the physics and engineering of air foil design, with a mathematician's viewpoint of trying to understand what's going on at the deepest level and to nail down the details with proof. The other article is her Retiring AMS Presidential Address "Mathematics to the rescue" (Notices, January 1999). This piece puts the spotlight on a few outstanding problems-weather prediction, molecular structure, and transonic flow-and throws the mathematical aspects into sharp relief. Morawetz moves seamlessly from nontechnical and insightful presentations of the physics, engineering, and mathematics to entertaining asides about the people involved. Both articles give a sense of her deep knowledge, as well as her immense charm and humor.

Morawetz is the first and only woman to have received the AMS Steele Prize for Lifetime Achievement (2004); the same can be said for her receiving the AMS-SIAM Birkhoff Prize in Applied Mathematics (2006). She is also the first and only woman mathematician to have received the U.S. National Medal of Science (1998). In addition to a term as AMS president (1995-1996), Morawetz has served the Society in various capacities, including terms on the Board of Trustees and the Council. This long association with the AMS played a part in her decision, in celebration of her 90th birthday last year, to make a major donation to the Society. The gift from her and her husband, Herbert Morawetz, significantly increased the size of the long-underfunded Oswald Veblen Prize Fund, bringing it on a par with other AMS prize funds.

Veblen was a good friend of Morawetz's father, John Lighton Synge. How this friendship began is recounted in Synge's article "For the 100th birthday of the American Mathematical Society", which appeared in A Century of Mathematics in America: Part 1, edited by Peter Duren (AMS, 1988). The article is a written version of a talk Synge gave at the AMS Centennial Celebration in 1988. In the article, he recalls an AMS meeting he attended in December 1921 in Toronto. He had come to Toronto from Dublin the year before and found few colleagues with mathematical interests similar to his own. His encounter with Veblen at that AMS meeting and the kindness and consideration Veblen showed were important to Synge as he made his way in mathematics in a new land.

At the time Synge wrote the article, he was 91 years old, the same age his daughter is now. One hears in his article an echo of the lively intellect and warmth of Cathleen Synge Morawetz. For those qualities and for her many contributions to mathematics and to the profession, she has evoked great fondness in the mathematical community. Happy 91st, Cathleen! 